\title{
Osteopilus septentrionalis (Cuban Treefrog).
}

\section{Distribution.}

Date of observation: 17 May 2011. Location: Puerto Rico: Cabo Rojo; Boquerón. Coordinates: 18.032011, -67.173192. Elevation: 2 m. Voucher: image. After heavy rains (more than 4 inches) at least three males were calling from a tree, above a pool of water. This is a range extension for this introduced, invasive, species to the southwestern corner of the island. Identification verified by Jose A. Colon.

Alcides L. Morales, Puerto Rican Ornithological Society Inc., 1605 Carr 477, Quebradillas, Puerto Rico, 678, Puerto

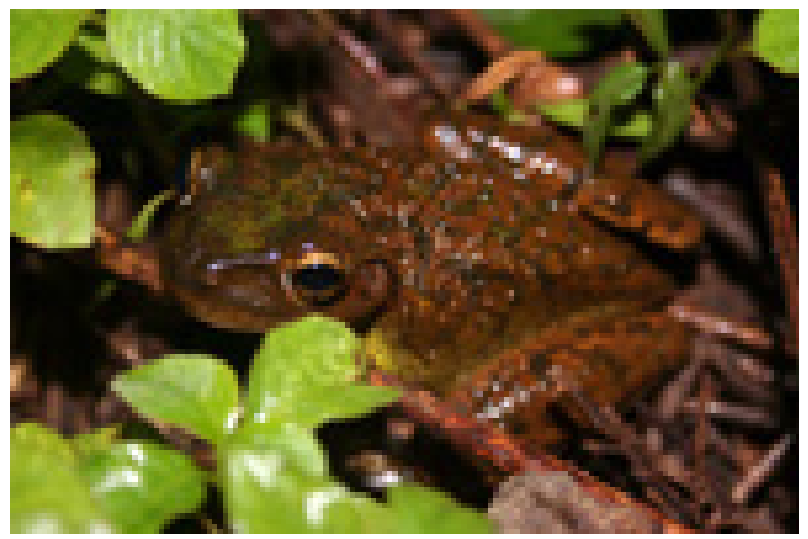
Rico, alcidesl.morales@yahoo.com.

Citation: Morales AL. 2011. Osteopilus septentrionalis (Cuban Treefrog). Distribution. Caribbean Herpetology 20:1.

Published online 20 June 2011 